\title{
Spirofluorene-Based Blue Phosphorescent Organic Light-Emitting Diode with Improved Efficiency Using Co-Host Structure
}

\author{
Mingli Sun, ${ }^{*, a}$ Yuqiao Guan, ${ }^{b}$ Bin Liu, ${ }^{b}$ Shufen Chen, ${ }^{, b}$ Yang Zhang, ${ }^{a}$ Hongtao Cao, ${ }^{b}$ \\ Linghai Xie, ${ }^{b}$ Yan Qian, ${ }^{b}$ and Wei Huang ${ }^{*, b}$ \\ ${ }^{a}$ Department of Chemistry, College of Science, Northeast Forestry University, Harbin, Heilongjiang 150040, China \\ ${ }^{b}$ Center for Molecular Systems and Organic Devices (CMSOD), Key Laboratory for Organic Electronics and \\ Information Displays \& Institute of Advanced Materials (IAM), National Synergistic Innovation Center for \\ Advanced Materials (SICAM), Nanjing University of Posts \& Telecommunications, Nanjing, Jiangsu 210023, China
}

\begin{abstract}
Highly efficient blue phosphorescent organic light-emitting diode (OLED) is achieved by using a blend of biphenyl (spiro[fluorene-9,9'-xanthen]-2-yl) phosphine oxide (SFX2PO) and various of hole- or electron-transporting materials such as di-[4-( $N, N$-di-p-tolyl-amino)-phenyl]cyclohexane (TAPC), 2,2',2"-(1,3,5-benzinetriyl)-tris(1phenyl-1- $H$-benzimidazole) (TPBi) and 4,4',4"-tris(carbazol-9-yl)triphenylamine (TCTA). The results show that TCTA and SFX2PO can partially form exciplex and have better charge carrier balance performance. The driving voltage and efficiency are improved in a multi-player device with TCTA and SFX2PO as the co-host. The device shows a maximum current efficiency of $22.75 \mathrm{~cd} \bullet \mathrm{A}^{-1}$, which is nearly two folds over the device using SFX2PO or phosphine oxide spirobifluorene derivative (SPPO1) as a single host.
\end{abstract}

Keywords spirofluorene, organic light-emitting diode, co-host, exciplex, bipolar

\section{Introduction}

Spirofluorene-based host materials for blue phosphorescent organic light-emitting diodes (OLEDs) has been applied widely due to unique spiro-structure with the advantages of highly thermal stability and steric hindrance. ${ }^{[1-4]}$ Among them, spiro[fluorene-9,9'-xanthene] (SFX) is expected to replace the well-known spirobifluorene due to its concise and effective synthesis method. ${ }^{[5,6]}$ However, the performance of the device based on SFX hosts can still not transcend that of the device based on spirobifluorene hosts. ${ }^{[7]}$ Therefore, developing new molecular structure or new methods to improve the device performance will be urgently needed for SFX-based hosts. To increase the device efficiency, a lot of SFX-based host materials have been developed to match the phosphorescent dopant and neighboring charge transporting materials in multi-layer electroluminescent devices. ${ }^{[10-13]}$ However, SFX derivatives as single host materials can still not achieve higher efficiency than spirobifluorene derivatives in blue phosphorescent OLEDs.

As is well known, bipolar host materials have been considered to be most effective due to their excellent charge carrier transporting property for blue phospho- rescent OLEDs. Generally, there are two ways to construct bipolar hosts. One way is to synthesize a new material consisting of a hole transporting unit and an electron transporting unit. ${ }^{[14-21]}$ The other way is to use a co-host composed of a hole transporting material and an electron transporting material. ${ }^{[22-24]}$ Since the latter approach can easily be operated avoiding a new synthesis, a lot of phosphorescent OLEDs have been fabricated through this approach and achieved high efficiency. ${ }^{[25-30]}$ Especially, using an exciplex forming co-host for phosphorescent OLEDs becomes a newly effective method to improve the device efficiency recently. ${ }^{[31-37]}$

In this paper, we selected di-[4-( $N, N$-di-p-tolylamino)-phenyl]cyclohexane (TAPC), 2,2',2"-(1,3,5benzinetriyl)-tris(1-phenyl-1- $H$-benzimidazole) (TPBi) and 4,4',4"-tris(carbazol-9-yl)triphenylamine (TCTA) to form co-host with biphenyl (spiro[fluorene-9,9'-xanthen]-2-yl) phosphine oxide (SFX2PO) for blue phosphorescent OLEDs. The results showed that the current efficiency of the device with SFX2PO and TCTA as co-host was improved twice as much as that of the device based on single SFX2PO host. Meanwhile, the efficiency also exceeded that of the device based on phosphine oxide spirobifluorene derivative (SPPO1).

\footnotetext{
* E-mail: sm198@163.com, iamsfchen@njupt.edu.cn,wei-huang@njupt.edu.cn

Received September 15, 2015; accepted September 25, 2015; published online October 8, 2015.

Supporting information for this article is available on the WWW under http://www.genchemistry.org.
} 


\section{Experimental}

\section{Materials and measurements}

All the reagents and solvents used for synthesis of the title compounds were purchased from J\&K Scientific and Energy Chemical and used without further purification. Except for SFX2PO, other compounds for electroluminescent devices were purchased from Aldrich or TCI (Shanghai) Development Co., Ltd and used directly.

Cyclic voltammetry (CV) measurement was performed using an electrochemical analyzer (CHI600C) with a platinum sheet working electrode, a platinum wire counter electrode, and a silver/silver nitrate $\left(\mathrm{Ag} / \mathrm{Ag}^{+}\right)$reference electrode to estimate the highest occupied molecular orbital (HOMO) and lowest unoccupied molecular orbital (LUMO) levels of the SFX2PO. Photoluminescence (PL) spectra of the used materials at room temperature were measured by a fluorescent spectrophotometer (Shimadzu RF-5301PC).

\section{Synthesis}

Adhering to the concept of green organic semiconductor, ${ }^{[38]}$ we synthesized SFX2PO by concise one-step reaction with diphenylphosphine oxide and 2-bromospiro[fluorene-9,9'-xanthene](BrSFX) (Scheme 1), which differed from our previously published method needing three steps. ${ }^{[10]} \mathrm{A}$ mixture of the BrSFX (1 equiv.), diphenylphosphine oxide (1 equiv.), $\mathrm{Pd}(\mathrm{OAc})_{2} \quad(0.05 \quad$ equiv. $)$, $1,1^{\prime}$-bis(diphenylphosphino)ferrocene ( 0.1 equiv.) and triethylamine (TEA) (1.2 equiv.) in dimethyl sulphoxide (DMSO) solvent was heated to $100{ }^{\circ} \mathrm{C}$ and stirred for 2 h. After cooling, dichloromethane was added to the reaction mixture, followed by extracting with water to remove DMSO. Then, the organic phase was dried with anhydrous $\mathrm{MgSO}_{4}$. The solvent was removed in vacuo and the residue was purified by column chromatography on silica gel $[V$ (dichloromethane) $/ V$ (ethyl acetate)]. Finally, the white powder product was obtained with the yield of $80 \%$. The characterizations of NMR and GC-MS were shown in Supporting Information (Figures $\mathrm{S} 1-\mathrm{S} 3)$.

Scheme 1 The synthetic route of SFX2PO.
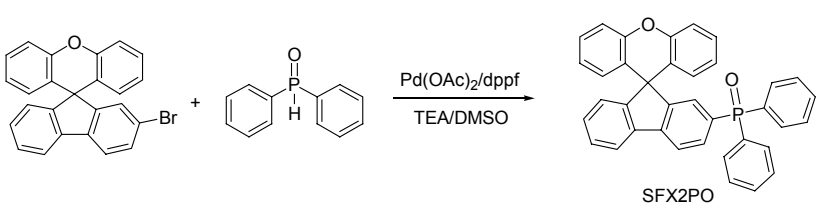

\section{Device fabrication}

In addition to PEDOT : PSS layer prepared by spin-coating method, all the other layers of the devices were fabricated by means of vacuum deposition with ITO glass (10 $\Omega /$ square) as the substrate. The ITO surface was scrubbed and ultrasonic cleaned sequentially with detergent, acetone, ethanol, and deionized water. Next, the substrate was dried in an oven for $1 \mathrm{~h}$, followed by ultraviolet-ozone chamber for 5 min. PEDOT : PSS layer with a thickness of $20 \mathrm{~nm}$ was spin-coated directly onto the ITO glass at a spin speed of $2000 \mathrm{rpm}$ for $60 \mathrm{~s}$, and thermally annealed at $120{ }^{\circ} \mathrm{C}$ for $30 \mathrm{~min}$ under vacuum condition. After the organic layers were vapor deposited under a vacuum (about $4.0 \times 10^{-4} \mathrm{~Pa}$ ) at a rate of $1-2 \AA \cdot \mathrm{s}^{-1}$, 100 -nm-thick Al was covered directly on the organic layers serving as cathode. The cathode area defines an active device area of $2 \times 2 \mathrm{~mm}^{2}$ through a shadow mask. The current-voltage-luminance (J-V-L) characteristics were measured with a PR650 spectrascan spectrometer and a Keithley 2400 programmable voltage-current source. All the experiments and measurements were carried out at room temperature under ambient conditions.

\section{Results and Discussion}

TAPC, TPBi and TCTA were selected as co-host with SFX2PO blends and FIrpic as the blue dopant for blue PHOLEDs, respectively. The HOMO and LUMO of SFX2PO were -6.23 and $-2.29 \mathrm{eV}$ estimated from cyclic voltammetry curve (Figure S4). Consequently, the band gap $\left(E_{\mathrm{g}}\right)$ was $3.94 \mathrm{eV}$ which is consistent with that estimated from the fluorescent spectrum of SFX2PO in dichloromethane solution $\left(\lambda_{\mathrm{em}}=321 \mathrm{~nm}, E_{\mathrm{g}}\right.$ $=3.86 \mathrm{eV}){ }^{[10]}$ Due to aggregation effect the fluorescent spectrum of SFX2PO film shows red-shift and the band gap is reduced (Table 1). To investigate the optical properties of co-host, the normalized fluorescent spectra of SFX2PO, TAPC, TPBi, TCTA and their co-spin-coated films with the weight ratio of $1: 1$ were measured (Figure 1). The emission wavelength of each material is summarized in Table 1. The films of SFX2PO, TAPC, TPBi and TCTA showed the maximum emission peak of $375,378,377$, and $405 \mathrm{~nm}$. The films of TAPC : SFX2PO and TPBi : SFX2PO exhibited maximum emission at 457 and $377 \mathrm{~nm}$ which were equivalent to the secondary emission peak of TAPC and the maximum emission peak of TPBi, respectively. However, the maximum emission peak of TCTA:

Table 1 The comparison of the fluorescence emission and optical band gap of the used compounds in films

\begin{tabular}{ccc}
\hline Film & $\lambda_{\mathrm{em}} / \mathrm{nm}$ & Band gap $^{a} / \mathrm{eV}$ \\
\hline SFX2PO & $375,341^{\mathrm{s}}$ & 3.31 \\
TAPC & $378,453^{\mathrm{s}}$ & 3.28 \\
TPBi & 377 & 3.29 \\
TCTA & $405,492^{\mathrm{s}}$ & 3.06 \\
TAPC:SFX2PO & $457,375^{\mathrm{s}}$ & 2.71 \\
TPBi:SFX2PO & 377 & 3.29 \\
TCTA:SFX2PO & $470,392^{\mathrm{s}}$ & 2.64 \\
\hline
\end{tabular}

${ }^{a}$ Values are computed from the maximum fluorescent emission wavelength; "“s" means weak shoulder emission peak. 
SFX2PO was at $470 \mathrm{~nm}$, which showed red-shifted emission from those of SFX2PO and TCTA. But the energy of $2.64 \mathrm{eV}$ calculated from TCTA : SFX2PO emission peak was not consistent with the gap between the HOMO of SFX2PO and the LUMO of TCTA. This indicated that SFX2PO and TCTA molecules only achieved partly energy transfer and did not completely form an exciplex in the excited state. ${ }^{[31,32]}$

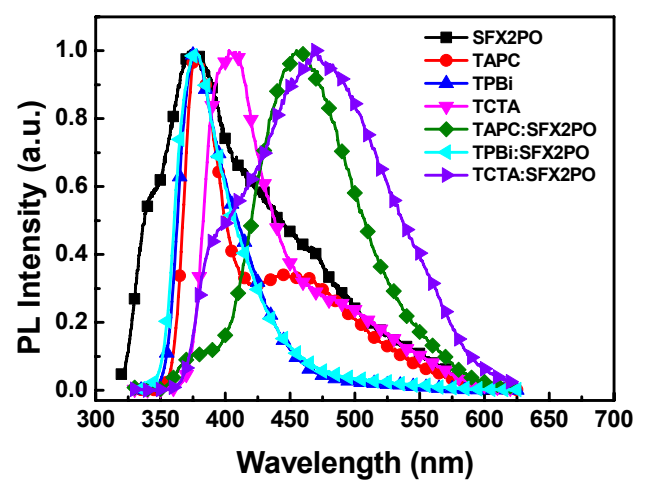

Figure 1 Emission spectra of SFX2PO, TAPC, TPBi, TCTA and their mixture films of TAPC : SFX2PO, TPBi : SFX2PO, and TCTA : SFX2PO at room temperature.

To investigate the action of co-host in blue phosphorescent OLEDs, a series of devices $A-E$ have been fabricated with multilayer configurations (Figure 2). The structures of device A-E were composed of ITO/PEDOT : PSS (20 nm)/TAPC $(10 \mathrm{~nm}) /$ hosts : Firpic $(10 \%, 30 \mathrm{~nm}) / \mathrm{TmPyPb}(50 \mathrm{~nm}) / \mathrm{LiF}(0.5 \mathrm{~nm}) / \mathrm{Al}$
(100 nm), where TAPC and TmPyPb served as hole- and electron-transporting layers. The hosts were composed of SPPO1, SFX2PO, TAPC : SFX2PO, TPBi : SFX2PO and TCTA : SFX2PO, respectively. The molecular structures of these organic compounds were shown in Figure 2. The current density-voltage-luminance $(\mathrm{J}-\mathrm{V}-\mathrm{L})$ characteristics, current efficiency-current density of devices $\mathrm{A}-\mathrm{E}$ were compared in Figure 3a, respectively.

The driving voltages of devices $\mathrm{A}-\mathrm{E}$ at $100 \mathrm{~cd} \bullet \mathrm{m}^{-2}$ were $4.54,4.23,3.79,4.90$, and $4.02 \mathrm{~V}$, respectively (Table 2). As can be seen from Figure 3a, the driving voltage of device $\mathrm{B}$ is lower than that of device A, which can be probably attributed to the weak bipolar transporting property of $\mathrm{SFX} 2 \mathrm{PO}^{[10]}$ over that of SPPO1.

Table 2 The device performances of device A-E

\begin{tabular}{ccc}
\hline Device & Driving voltage $^{a} / \mathrm{V}$ & Current efficiency $^{b} /\left(\mathrm{cd}^{\circ} \mathrm{A}^{-1}\right)$ \\
\hline $\mathrm{A}$ & $4.54,5.92,8.47$ & $13.78,5.99$ \\
$\mathrm{~B}$ & $4.23,5.40,9.51$ & $11.70,5.35$ \\
$\mathrm{C}$ & $3.79,5.33,-$ & $11.76,3.40$ \\
$\mathrm{D}$ & $4.90,8.33,-$ & $5.87,1.43$ \\
$\mathrm{E}$ & $4.02,5.15,5.98$ & $22.75,14.24$ \\
$\mathrm{~F}$ & $6.83,8.93,10.47$ & $24.43,17.60$ \\
\hline
\end{tabular}

${ }^{a}$ In the turn of at $100 \mathrm{~cd} \cdot \mathrm{m}^{-2}$, at $1000 \mathrm{~cd} \cdot \mathrm{m}^{-2}$ and at $5000 \mathrm{~cd} \bullet \mathrm{m}$ ${ }^{-2} ;{ }^{b}$ In the turn of maximum efficiency and at $100 \mathrm{~mA} \cdot \mathrm{cm}^{-2}$; “-” means no obtainment.

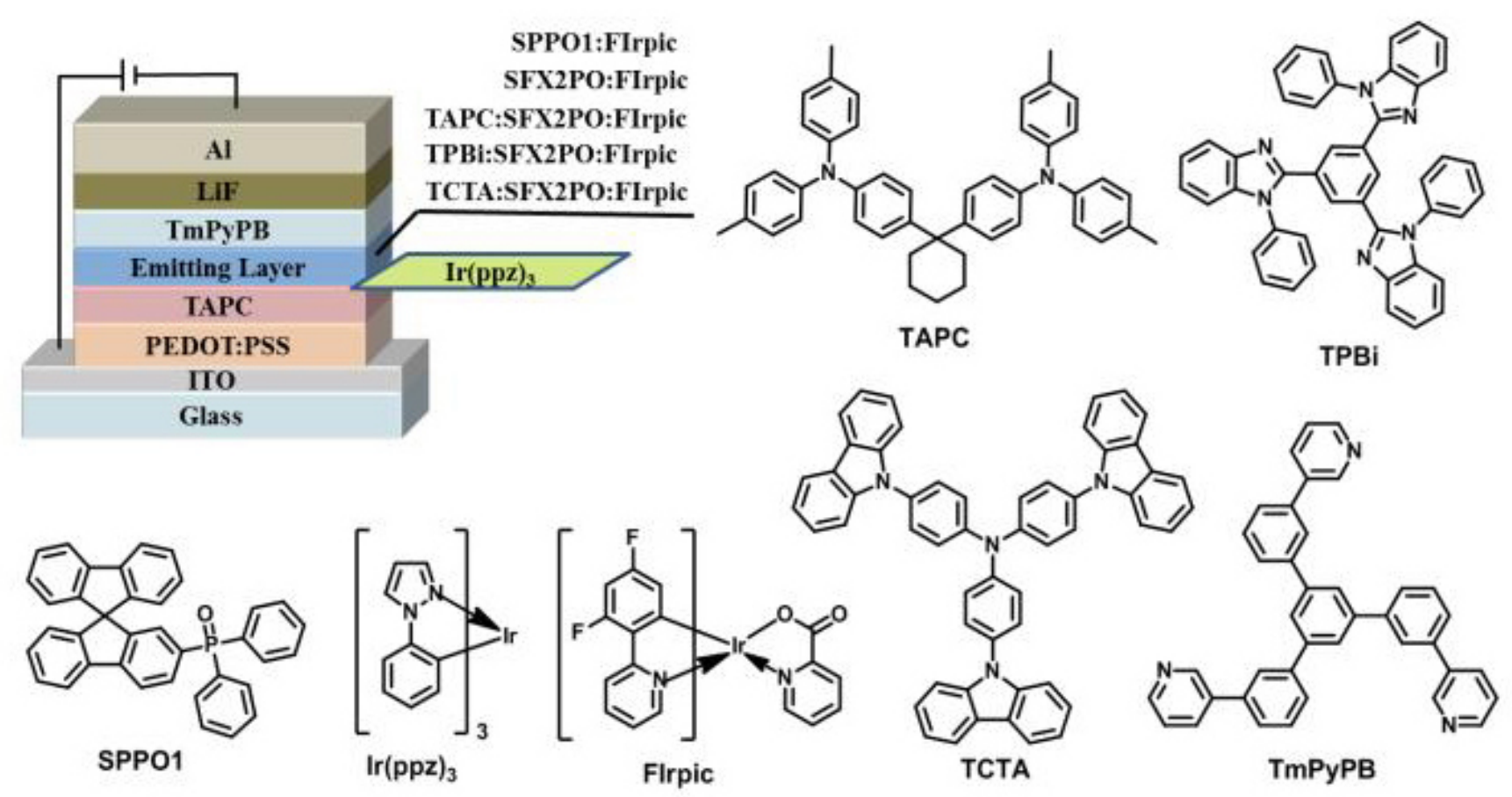

Figure 2 The structure diagram of devices A-E and chemical structures of the used materials. 

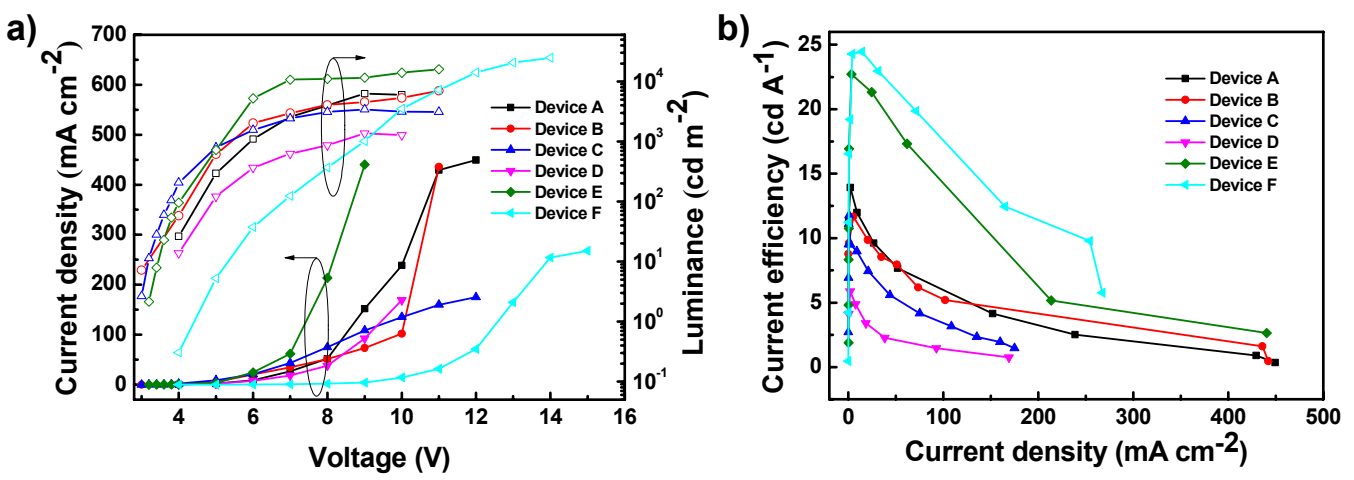

Figure 3 Characteristics of devices A-F: (a) current density-voltage-luminance (J-V-L) curves (b) current efficiency-current density characteristics.

The driving voltage of device $\mathrm{C}$ and device $\mathrm{E}$ can be reduced in comparison to that of device $\mathrm{B}$, which is because the introduction of TAPC and TCTA improve the hole-transporting performance of the single host that can better balance the charge carrier transport of the co-hosts. While device $\mathrm{D}$ shows higher driving voltage than that of device $\mathrm{B}$ because the introduction of TPBi make the co-host of TPBi : SFX2PO nearly become electron-only transporting materials. Along with the increase in luminance, the driving voltage of these devices increase obviously. But at $5000 \mathrm{~cd} \cdot \mathrm{m}^{-2}$ the driving voltage of device $\mathrm{E}$ is only $5.98 \mathrm{~V}$ which is much lower than that of other devices. This is supposed to be attributed to the narrow band gap of TCTA : SFX2PO film (Table 1) and charge carrier injection/transport balance of the co-host.

In addition, the current efficiency curves of device $\mathrm{A}-\mathrm{E}$ were constructed in order to further compare the effectiveness of several co-hosts (Figure 3b). The device $\mathrm{B}$ exhibited a maximum current efficiency of $11.70 \mathrm{~cd}$ • $\mathrm{A}^{-1}$ using SFX2PO as single host, which was lower than that of device A (13.78 $\mathrm{cd} \cdot \mathrm{A}^{-1}$, Table 2). The maximum current efficiency of device $\mathrm{C}$ was equivalent to that of device $\mathrm{B}$, but the efficiency was lower than that of device $\mathrm{B}$ with the increase of the current density (Figure $3 b$ ). The current efficiency of device D was obviously lower than that of device $\mathrm{B}$ due to the poor charge balance performance of the TPBi : SFX2PO co-host. However, the maximum current efficiency of device $\mathrm{E}$ was nearly twice as that of device $\mathrm{B}$ and the difference reached about three times at $100 \mathrm{~mA} \cdot \mathrm{cm}^{-2}$ (Table 2) which indicated the efficiency roll-off of the device $\mathrm{E}$ was relatively lower. The electroluminescent (EL) spectra of device A-E all exhibited blue emission at $474 \mathrm{~nm}$ attributed to FIrpic (Figure 4). However, it was noticed that device $\mathrm{E}$ prohibited the green emission band which emerged at about $584 \mathrm{~nm}$ in the device BD.

Furthermore, we fabricated the device $F$ which added $\operatorname{Ir}(\mathrm{ppz})_{3}$ between the hole-transporting layer and emit-

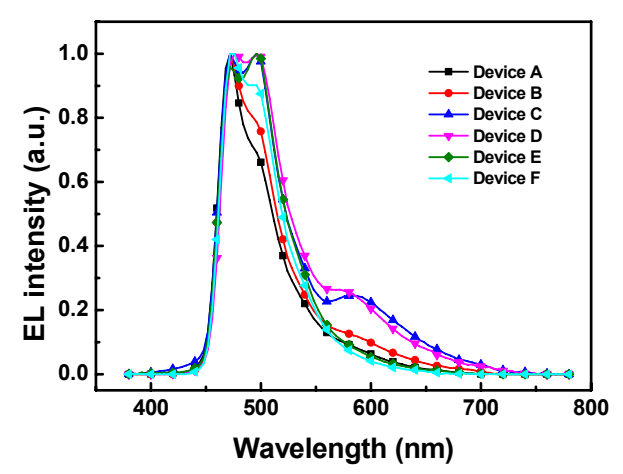

Figure 4 Normalized EL spectra of devices A-F.

ting layer as electron-blocking layer (Figure 2). Though the current efficiency of device $\mathrm{F}$ achieved $24.43 \mathrm{~cd}$ • $\mathrm{A}^{-1}$ and was higher than that of device $\mathrm{E}$, the driving voltage of device $\mathrm{F}$ was also significantly increased. This indicated that the introduction of the functional device layer was unfavorable to the driving voltage.

\section{Conclusions}

In summary, we used SFX2PO to construct co-host structure with TAPC, TPBi and TCTA for blue phosphorescent OLEDs and explored the probability of the formation of exciplex. It was found that TCTA and SFX2PO could not completely form exciplex, but the device based on the TCTA : SFX2PO co-host exhibited higher efficiency than the device based on single host of SFX2PO in comparison to TAPC: SFX2PO and TPBi : SFX2PO. Meanwhile, the strategy of using co-host structure achieved high efficiency successfully beyond that of SPPO1-based blue phosphorescent OLED. The maximum current efficiency of $22.75 \mathrm{~cd} \cdot$ $\mathrm{A}^{-1}$ was obtained from the device based on the TCTA : SFX2PO due to good charge balance performance of the co-host. And this device also achieved a low driving 
voltage and the value was only $5.98 \mathrm{~V}$ even at the luminescence of $5000 \mathrm{~cd} \cdot \mathrm{m}^{-2}$ which facilitated the application of the electronic portable equipment.

\section{Acknowledgement}

Mingli Sun express sincere gratitude to the Fundamental Research Funds for Central Universities (No. 2572014BB21). Shufen Chen thanks the financial support from the National Natural Science Foundation of China (No. 61274065).

\section{References}

[1] Saragi, T. P. I.; Spehr, T.; Siebert, A.; Fuhrmann-Lieker, T.; Salbeck, J. Chem. Rev. 2007, 107, 1011.

[2] Sun, M. L.; Xu, R. C.; Xie, L. H.; Wei, Y.; Huang, W. Chin. J. Chem. 2015, 33, 815.

[3] Sun, M. L.; Lin, D. Q.; Xie, L. H.; Huang, W. Chin. J. Liq. Cryst. Disp. 2014, 29, 22.

[4] Lin, D. Q.; Sun, M. L.; Wei, Y.; Xie, L. H.; Zhang, X. N.; Huang, W. Chin. Sci. Bull. 2015, 60, 1.

[5] Xie, L. H.; Liu, F.; Tang, C.; Hou, X. Y.; Hua, Y. R.; Fan, Q. L.; Huang, W. Org. Lett. 2006, 8, 2787.

[6] Swager, T. M.; Dane, E. L. Synfacts 2006, 9, 0904.

[7] Jeon, S. O.; Yook, K. S.; Joo, C. W.; Lee, J. Y. Appl. Phys. Lett. 2009, 94, 013301.

[8] Jang, S. E.; Joo, C. W.; Jeon, S. O.; Yook, K. S.; Lee, J. Y. Org. Electron. 2010, 11, 1059.

[9] Jeon, S. O.; Lee, J. Y. Org. Electron. 2011, 12, 1893.

[10] Zhao, J.; Xie, G. H.; Yin, C. R.; Xie, L. H.; Han, C. M.; Chen, R. F.; Xu, H.; Yi, M. D.; Deng, Z. P.; Chen, S. F.; Zhao, Y.; Liu, S. Y.; Huang, W. Chem. Mater. 2011, 23, 5331.

[11] Qian, Y.; Xie, G.; Chen, S.; Liu, Z.; Ni, Y.; Zhou, X.; Xie, L.; Liang, J.; Zhao, Y.; Yi, M.; Zhao, Y.; Wei, W.; Huang, W. Org. Electron. 2012, 13, 2741.

[12] Sun, M. L.; Yue, S. Z.; Lin, J. R.; Ou, C. J.; Qian, Y.; Zhang, Y.; Li, Y.; Wei, Q.; Zhao, Y.; Xie, L. H.; Huang, W. Synth. Met. 2014, 195, 321.

[13] Qian, Y.; Ni, Y. R.; Yue, S. Z.; Li, W. W.; Chen, S. F.; Zhang, Z. S.; Xie, L. H.; Sun, M. L.; Zhao, Y.; Huang, W. RSC Adv. 2015, 5, 29828.

[14] Tao, Y. T.; Yang, C. L.; Qin, J. G. Chem. Soc. Rev. 2011, 40, 2943.

[15] Holmes, R. J.; Forrest, S. R.; Tung, Y. J.; Kwong, R. C.; Brown, J. J.; Garon, S.; Thompson, M. E. Appl. Phys. Lett. 2003, 82, 2422.

[16] Williams, E. L.; Haavisto, K.; Li, J.; Jabbour, G. E. $A d v$. Mater. 2007, 19, 197.

[17] Su, S. J.; Sasabe, H.; Takeda, T.; Kido, J. Chem. Mater. 2008,
$20,1691$.

[18] Jeon, S. O.; Yook, K. S.; Joo, C. W.; Lee, J. Y. Adv. Mater. 2010, 22, 1872.

[19] Chaskar, A.; Chen, H. F.; Wong, K. T. Adv. Mater. 2011, 23, 3876.

[20] Bin, J. K.; Cho, N. S.; Hong, J. I. Adv. Mater. 2012, 24, 2911.

[21] Lee, C. W.; Yook, K. S.; Lee, J. Y. Org. Electron. 2013, 14, 1009.

[22] Liu, T. H.; Iou, C. Y.; Chen, C. H. Appl. Phys. Lett. 2003, 83, 5241.

[23] Liu, T. H.; Iou, C. Y.; Chen, C. H. Curr. Appl. Phys. 2005, 5, 218.

[24] Lee, J. H.; Lee, J. I.; Lee, J. Y.; Chu, H. Y. Org. Electron. 2009, 10, 1529.

[25] Chen, Y. H.; Chen, J. S.; Zhao, Y. B.; Ma, D. G. Appl. Phys. Lett. 2012, 100, 213301.

[26] Jou, J. H.; Yu, H. H.; Lin, Y. X.; Tseng, J. R.; Peng, S. H.; Jou, Y. C.; Lin, C. H.; Shen, S. M.; Hsieh, C. Y.; Wei, M. K.; Lin, D. H.; Wang, C. C.; Chen, C. C.; Tung, F. C.; Chen, S. H.; Wang, Y. S. J. Mater. Chem. C 2013, 1, 5110.

[27] Jang, S. E.; Yook, K. S.; Lee, J. Y. Org. Electron. 2010, 11, 1154.

[28] Sun, J.; Zhang, Y. X.; Zhang, H. K.; Su, Z. S.; He, H. X.; Tian, M.; Zhu, X.; Li, H. Y.; Dou, Q. C. Ecs J. Solid State Sci. Technol. 2014, 3, Q212.

[29] Duan, L.; Hou, L. D.; Lee, T. W.; Qiao, J.; Zhang, D. Q.; Dong, G. F.; Wang, L. D.; Qiu, Y. J. Mater. Chem. 2010, 20, 6392.

[30] Doh, Y. J.; Park, J. S.; Jeon, W. S.; Pode, R.; Kwon, J. H. Org. Electron. 2012, 13, 586.

[31] Shin, H.; Lee, S. H.; Kim, K. H.; Moon, C. K.; Yoo, S. J.; Lee, J. H.; Kim, J. J. Adv. Mater. 2014, 26, 4730.

[32] Seo, S.; Shitagaki, S.; Ohsawa, N.; Inoue, H.; Suzuki, K.; Nowatari, H.; Yamazaki, S. Japan. J. Appl. Phys. 2014, 53, 042102.

[33] Park, Y. S.; Lee, S.; Kim, K. H.; Kim, S. Y.; Lee, J. H.; Kim, J. J. Adv. Funct. Mater. 2013, 23, 4914.

[34] Lee, S.; Kim, K. H.; Limbach, D.; Park, Y. S.; Kim, J. J. $A d v$. Funct. Mater. 2013, 23, 4105.

[35] Lee, S.; Limbach, D.; Kim, K. H.; Yoo, S. J. Park, Y. S.; Kim, J. J. Org. Electron. 2013, 14, 1856.

[36] Kim, S. Y.; Jeong, W. I.; Mayr, C.; Park, Y. S.; Kim, K.-H.; Lee, J. H.; Moon, C. K.; Brütting, W.; Kim, J. J. Adv. Funct. Mater. 2013, 23, 3896.

[37] Kim, K. H.; Moon, C. K.; Lee, J. H.; Kim, S. Y.; Kim, J. J. Adv. Mater. 2014, 26, 3844.

[38] Sun, M. L.; Zhu, W. S.; Zhang, Z. S.; Ou, C. J.; Xie, L. H.; Yang, Y.; Qian, Y.; Zhao, Y.; Huang, W. J. Mater. Chem. C 2015, 3, 94. 